\title{
Hepatitis A outbreak in an Orthodox Jewish community in London, July 2010
}

M Edelstein ${ }^{1}$, D Turbitt ${ }^{2}$, K Balogun³, J Figueroa4, G Nixon (grainne.nixon@hpa.org.uk)1

1. North East and Central London Health Protection Unit, London, United Kingdom

2. North East and North Central Health Protection Unit, London, United Kingdom

3. Immunisation, Hepatitis and Blood Safety Department, Health Protection Agency Centre for Infections, London, United Kingdom

4. National Health Service City and Hackney Department of Public Health, London, United Kingdom

Citation style for this article:

Edelstein M, Turbitt D, Balogun K, Figueroa J, Nixon G. Hepatitis A outbreak in an Orthodox Jewish community in London, July 2010. Euro Surveill.

2010;15(37):pii=19662. Available online: http://www.eurosurveillance.org/ViewArticle. aspx?Articleld=19662

Article published on 16 September 2010

A cluster of hepatitis A cases in the Orthodox Jewish community in London, United Kingdom in July 2010 has triggered extensive contact tracing and vaccination. Two primary cases imported from a common source in Israel and three secondary cases have resulted in immunisation of over 900 contacts to date. Rapid response by local public health, primary care services and a dedicated community health team, and active hepatitis $A$ vaccination rather than immunoglobulin treatment were used to avert a larger outbreak.

\section{Background}

The over 20,000-strong Orthodox Jewish (0J) community in London, United Kingdom, is the largest in Europe. A number of infectious disease outbreaks have occurred in this community in the last fifteen years, including hepatitis A [unpublished data], shigellosis [unpublished data], and measles [1]. Outbreaks of hepatitis A have also been described in other OJ communities in Canada [2] and the United States [3]. Vaccine uptake in the community is traditionally low, although this is not due to ideological reluctance [1]. Factors that facilitate rapid spread of infection in this community are: large families with a high proportion of young children, considerable household overcrowding, large numbers of children in schools, close interaction within the community and close and frequent contact with members of other 0 J communities [3].

\section{Situation and management}

In July 2010, acute symptomatic hepatitis A infection was reported in two members of the OJ community in London, a person in their 50 (Case 1) and a person in their late 6os (Case 2). Both cases had travelled to Israel in mid-June and independently attended the same event in Jerusalem. They also stayed in the same hotel in southern Israel, but had no direct contact and did not travel together. Case 1 had onset of symptoms in mid-July and Case 2 had onset of symptoms in late July, suggesting that they had a common exposure in Israel. Molecular sequencing was done in the UK and showed $99.8 \%$ homology between the viruses isolated from the two cases. Phylogenetic analysis of these sequences is currently ongoing.

In the UK, post-exposure prophylaxis immunisation against hepatitis $A$ is recommended for household and sexual contacts of a confirmed case, within 14 days of symptom onset in the case. Those aged over 50 years or with chronic liver disease or chronic hepatitis B or C are also offered human normal immunoglobulin (HNIG) [4].

A total of 69 family contacts were identified in six different English health regions and in Switzerland. They included a large number of children in the families as well as many contacts who did not reside in one of the two cases' households but had either stayed with a case or had eaten food prepared by them during the infectious period. Immunisation took place within 14 days after exposure in a variety of primary and secondary care settings, depending on availability of vaccine and the location of the case. Israeli public health services were notified of the travel-related cases but did not report any outbreaks or increase in reported cases of hepatitis A epidemiologically linked to Jerusalem or southern Israel.

In addition to immunisation of contacts, local general practitioners (GPs) who provide primary care to this community were alerted and encouraged to proactively offer immunisation to members of the 0 J community. A tailored leaflet was produced and disseminated, promoting hand washing with soap and water to ensure hand washing would not be limited to ritual hand washing with water only. The leaflet also encouraged hepatitis $A$ vaccination for travelling members of the community.

Because contacts had been identified in many English health regions, a national enhanced surveillance questionnaire was developed to ensure timely reporting of linked cases outside London. 
A third case of hepatitis A (Case 3) was confirmed within two weeks of the first cases in a man in his late 20 s who had attended the event in Jerusalem but not stayed in the hotel in southern Israel. He is the son of Case 2 and had been in continuous contact with Case 2 during the infectious period. Case 3 and his family were not mentioned as contacts of case 2 and as such had not been vaccinated. Although the incubation period of Case 3 includes the event in Jerusalem (47 days from attendance to onset of symptoms), we think it more likely that he was a secondary case.

Eleven contacts of Case 3 were immunised, including his five children aged between two and eight years who had also been exposed to Case 2. The risk of subclinical infection in these younger contacts [5] and the potential for ongoing transmission to the wider 0 J community was assessed. It was agreed that all children and staff attending the same school/nursery as Case 3's children (over 300 persons) would be immunised directly at the school by community nurses.

Twelve days after Case 3 was confirmed one his children became symptomatic and was confirmed to have hepatitis A (Case 4). This case generated 24 new close contacts who were immediately vaccinated, and a further 469 children who attended a one-day activity camp with the case were invited for vaccination.

By late august, eight days after Case 4 was confirmed, a fifth clinically suspected case was reported in a 19 year-old relative of Case 2 who had been immunised as a close contact with Case 2 outside of the 14-day period. Sixty students at the yeshiva (a religious education institution for adults) where Case 5 studies and resides were invited for vaccination. The epidemiological curve and a summary of the contact vaccinations are presented in the Figure.

The deadline for vaccination of contacts with continuous exposure is based on a 14-day window from the date of onset of symptoms in the case; for contacts exposed after the case's onset of symptoms it is 14 days post exposure. All contacts identified and all services responsible for delivering vaccination were advised about these deadlines for vaccination.

\section{Conclusion}

Five cases of hepatitis A, two travel-related and three secondary cases, have been reported to the North East and Central London Health Protection Unit between late July and late August 2010. Through active contact tracing we identified a total of over 900 contacts of these cases. 104 family contacts and over 300 school contacts were vaccinated. About 500 contacts attending a day camp and 60 contacts from a religious education institution were invited for vaccination. Uptake in these two groups is unknown as vaccination has taken place in a variety of settings (GPs, walk-in centres and an emergency department) that do not notify us of vaccination. We think that uptake has been high judged

\section{FIGURE}

Epidemiological curve with a summary of contact vaccination, hepatitis A outbreak, London, July 2010 ( $\mathrm{n}=5$ )

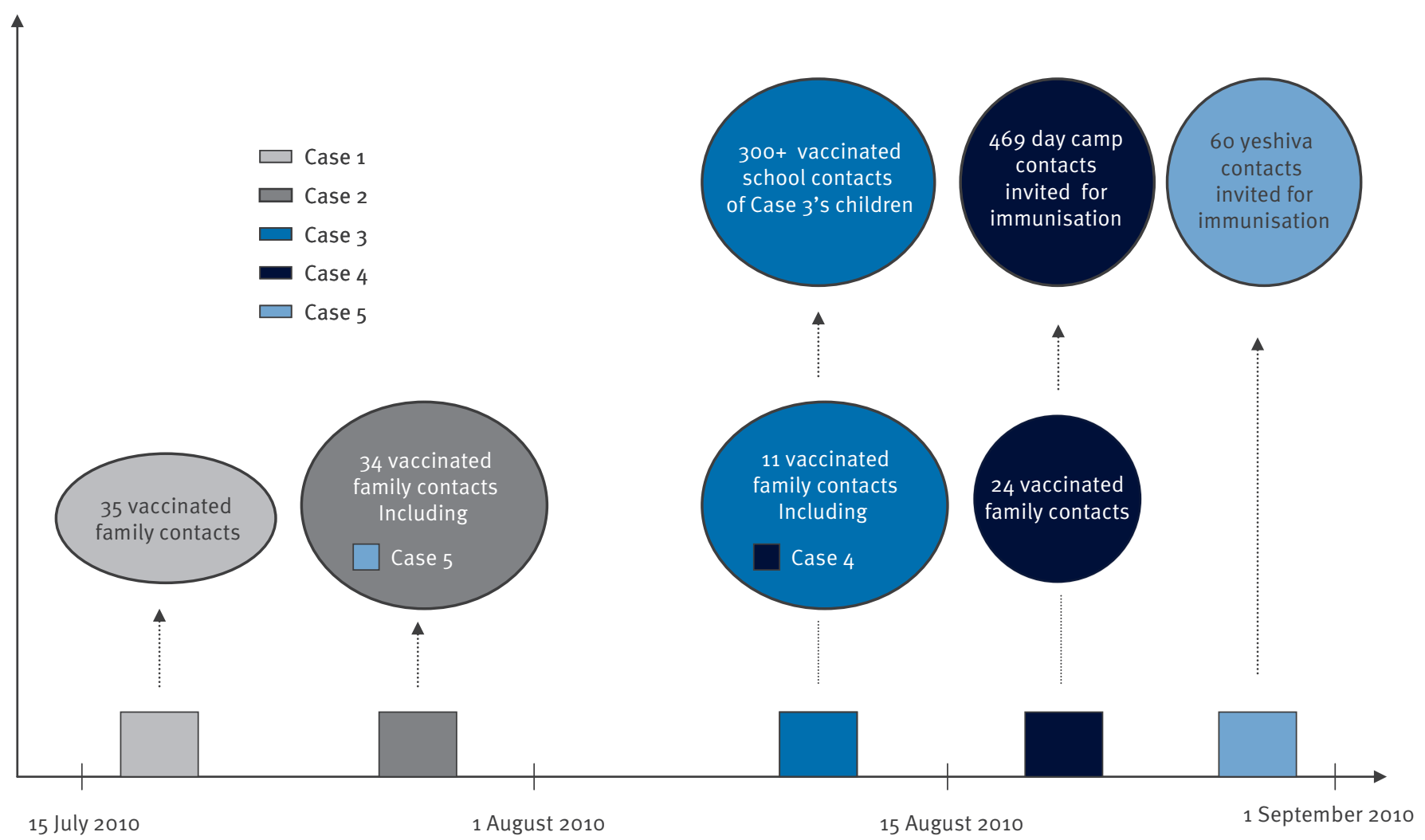


by the level of enquiries the health protection unit has received.

Given the progression of previous outbreaks of hepatitis $A$ in this and other 0 f communities there is a case for community-wide immunisation. However the current consensus of the incident team is that it would be disproportionate at this stage in response to five confirmed cases, four of whom are linked to the extended family of the index case (Case 2) who acquired the infection during travel to Israel. In addition, monovalent hepatitis $A$ vaccine has been used in this incident in preference or addition to HNIG. This combined approach should prevent onward transmission more effectively than HNIG alone [6]. It should also provide longer-term protection to recipients in the event that they are exposed to subsequent cases. This, combined with rapid contact tracing, a low threshold for offering immunisation and good cooperation between local public health and clinical services may have helped contain the spread of infection to date. No further cases have been reported at the time of publication of this report. However, the situation remains under review; if a case is reported that matches the molecular sequence profile of Cases 1-5 and does not have a travel history or clear epidemiological link to a known case, this will trigger a recommendation for a community immunisation programme targeting all children aged 1-11 years. Cases can be expected until late October 2010.

\section{References}

1. Ashmore J, Addiman S, Cordery R, Maguire H. Measles in North East and North Central London, England: a situation report. Euro Surveill. 2007;12(38):pii=3271. Available from: http:// www.eurosurveillance.org/ViewArticle.aspx?Articleld $=3271$

2. Deshaies D, Dion R, Valiquette L, Auger N. Immunization against hepatitis A during an outbreak in a Jewish Orthodox community - Quebec, 1997-1998. Can Commun Dis Rep. 1998;24(18):145-51.

3. Smith PF, Grabau JC, Werzberger A, editors. Hepatitis A in a Hasidic Jewish community, upstate New York. In: Proceedings of the 35th Annual Epidemic Intelligence Service (EIS) Conference, 1986 April 14-18, Atlanta, US. CDC, Atlanta, 1986:43.

4. Health Protection Agency (HPA). Guidance for the Prevention and Control of Hepatitis A Infection. London: HPA; 2009. $40 \mathrm{p}$ [Accessed Aug 2010]. Available from: www.hpa.org.uk/web/ HPAwebFile/HPAweb_C/1259152095231.

5. Jeong $\mathrm{SH}$, Lee HS. Hepatitis A: clinical manifestations and management. Intervirology. 2010;53(1):15-9. Epub 2010 Jan 5.

6. Sonder GJ, van Steenbergen JE, Bovee LP, Peerbooms PG, Coutinho RA, van den Hoek A. Hepatitis A immunity and seroconversion among contacts of acute hepatitis $A$ in Amsterdam, 1996-2000: an evaluation of current policy. Am J of Public Health. 2004;94:1620-6. 
